\title{
Financial Model Innovation of Agricultural Product Supply Chain Based on Integrated Operation
}

\author{
Li Chunhua ${ }^{1, *}$, Wang Peng ${ }^{2}$ \\ ${ }^{1,2}$ School of Logistics and Trade, Xi'an Eurasian University, Xi'an, Shanxi, 710000, China \\ *Corresponding author. Email: lichunhua@eurasia.edu
}

\begin{abstract}
There are many small and medium-sized enterprises in the agricultural product supply chain. These enterprises are faced with financing difficulties and high financing costs for a long time, and there are widespread trust crises and poor information transmission in the supply chain. Based on the integrated operation mechanism of the supply chain, this article discusses an internally driven agricultural supply chain financial model. With the help of blockchain technology, problems such as bill fraud, information silos, and information transmission are solved. While solving the financing problems of SMEs, this model integrates a large amount of social idle funds and improves the competitiveness of the entire supply chain.
\end{abstract}

Keywords: Integration, Supply chain finance, Model innovation

\section{INTRODUCTION}

At present, China's research on agricultural product supply chain mainly focuses on the design of agricultural product logistics, sales, and organizational models, while the systematic overall operation of domestic and foreign agricultural product supply chains lacks systematic analysis. However, various SMEs in the agricultural product supply chain have difficulties in financing and high financing costs, which cannot be solved well through current theoretical research. Compared with other fields, due to the different size and shape of enterprises, agricultural product supply chain finance is a more complex business model. This paper attempts to propose a supply chain finance suitable for agricultural product supply chain through the discussion of the operation mechanism of supply chain mode.

\section{COMMON SUPPLY CHAIN FINANCIAL MODELS AND PROBLEM ANALYSIS}

Supply chain finance (SCF) is a financing model in which banks link core enterprises with upstream and downstream enterprises to provide financial products and services. Its biggest feature is to find a large core enterprise in the supply chain. Taking the core enterprise as the starting point, it provides financial support for the supply chain. Common supply chain finance models include three types: The first, accounts receivable financing model, which belongs to the supply chain financing of the sales stage, mainly for small and medium-sized enterprises that provide materials to certain large enterprises. The second, future cargo rights financing model, which belongs to the supply chain financing in the procurement stage, mainly provides financing for certain small and medium-sized enterprises that need to purchase materials. The third, the financing mode of warehouse financing, which belongs to the supply chain financing in the operating stage, mainly for small and medium-sized enterprises with certain goods. The main problems of the current operation of these modes are as follows:

\subsection{Risk of bill fraud.}

Warehouse receipts, accounts receivable and other paper bills are easy to falsify during the circulation process, and most of the supply chain management is imperfect, making it difficult to achieve four-in-one.

\subsection{Enterprise information island}

There is no efficient connection between enterprises, banks, and supervisors. Information transmission mainly depends on paper documents, which increases the cost of acquiring information by banks. The difficulty of risk control increases, which increases the difficulty of financing for enterprises. 


\subsection{Core corporate credit cannot be passed across levels}

The core enterprise credit can only be passed to the first-tier enterprise, and other suppliers cannot use the core enterprise credit for financing, which limits the bank's customer base.

\subsection{High contract performance risk}

Relying solely on contractual constraints, the use of funds and repayments of financing companies are uncontrollable, loan funds of financing companies are easily diverted to other uses, and financing companies are susceptible to malicious defaults, making it difficult for banks to collect payments.

Therefore, the good operation of the supply chain financial model requires the establishment of an internally driven supply chain operation model, and the adoption of certain technical means to solve problems such as trust crises, information transfer, and bill fraud.

\section{INTEGRATED OPERATION MODE OF AGRICULTURAL PRODUCT SUPPLY CHAIN}

\subsection{Integrated operation mechanism of agricultural product supply chain}

For the current agricultural product industry in China, processing enterprises are easy to realize the brand promotion and large-scale production of agricultural products. Therefore, for the agricultural product supply chain, the core enterprises are the preferred processing enterprises with production scale and influence. Because it is difficult for upstream aquaculture enterprises to form standardized aquaculture processes, processing enterprises integrate upstream aquaculture enterprises on the basis of the existing supply chain, sign contracts with small cooperative organizations or farmers, supervise their production and operation, and provide technical guidance for breeding bases, in order to share the risks and benefits of breeding enterprises with processing enterprises. In addition, breeding enterprises can also develop their own breeding bases, realize large-scale contract production, and improve breeding technology according to market demand. Throughout the entire process, the core enterprise has technical support for the upstream aquaculture enterprise and is also responsible for product sales. At the same time, it integrates third-party logistics companies and logistics distribution centers of large chain supermarkets, etc. to carry out long-term strategic cooperation with it and obtain market demand information. In this way, the upstream and downstream are effectively connected through the core enterprise to realize the integrated operation mechanism of the supply chain led by the core enterprise, as shown in Figure 1.

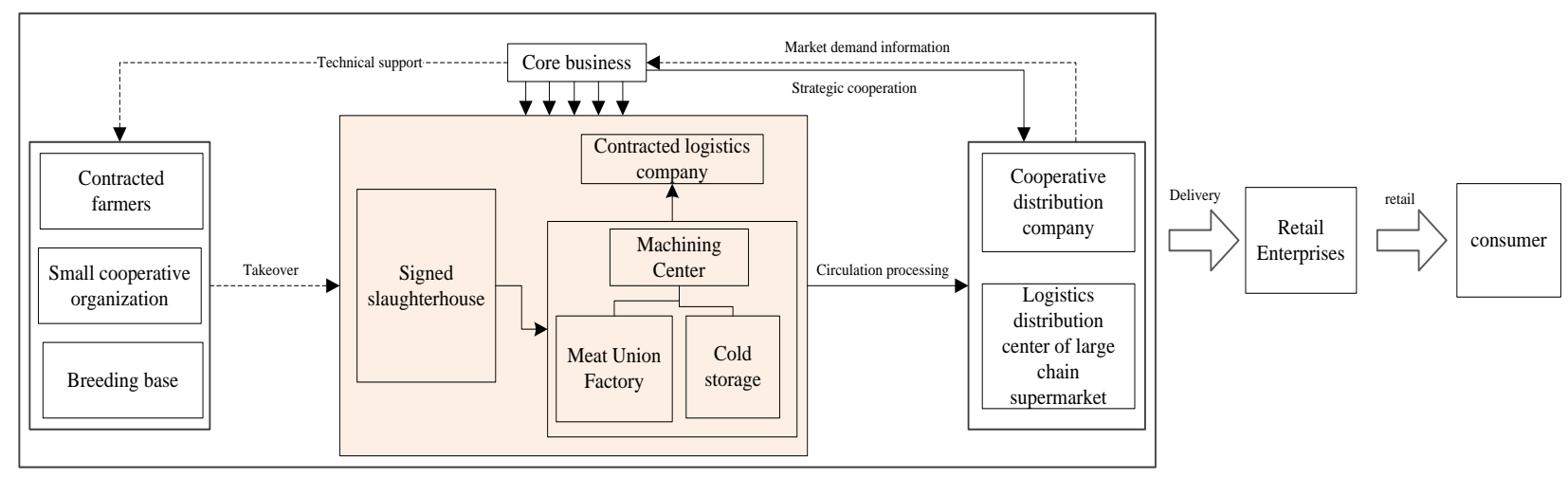

Figure 1 Integrated operation mechanism of agricultural breeding supply chain

\subsection{Integrated operation process of agricultural product supply chain}

Processing enterprises purchase agricultural products from upstream breeding enterprises and do relevant conduct testing. After passing the test, it will be slaughtered, processed, packaged, etc., and will be distributed by the contracted logistics company to the cooperative distribution enterprise or retail enterprise, or it can be directly distributed to the retail enterprise by the large-scale supermarket chain's own logistics distribution center, and finally reach the consumer.

\section{FINANCIAL MODEL INNOVATION FOR AGRICULTURAL SUPPLY CHAIN}

\subsection{New model of agricultural supply chain finance}

As a partner of core enterprises, commercial banks and other financial institutions rely on the core enterprise's dominant position to establish a supply 
chain financial platform. This platform is built and operated by financial institutions to collect and publish loan demand and solicit investment. With the help of distributed accounting technology, and with the help of core companies, financial institutions check and collect the operations, capital operations, and market sales of various companies, and analyze them to announce the credit rating of each company. This model ensures the authenticity of bills through blockchain technology, solves the crisis of trust and the cross-level transmission of information. According to different roles, enterprises in the supply chain have different information access rights. Information, the new model of agricultural supply chain finance is shown in Figure

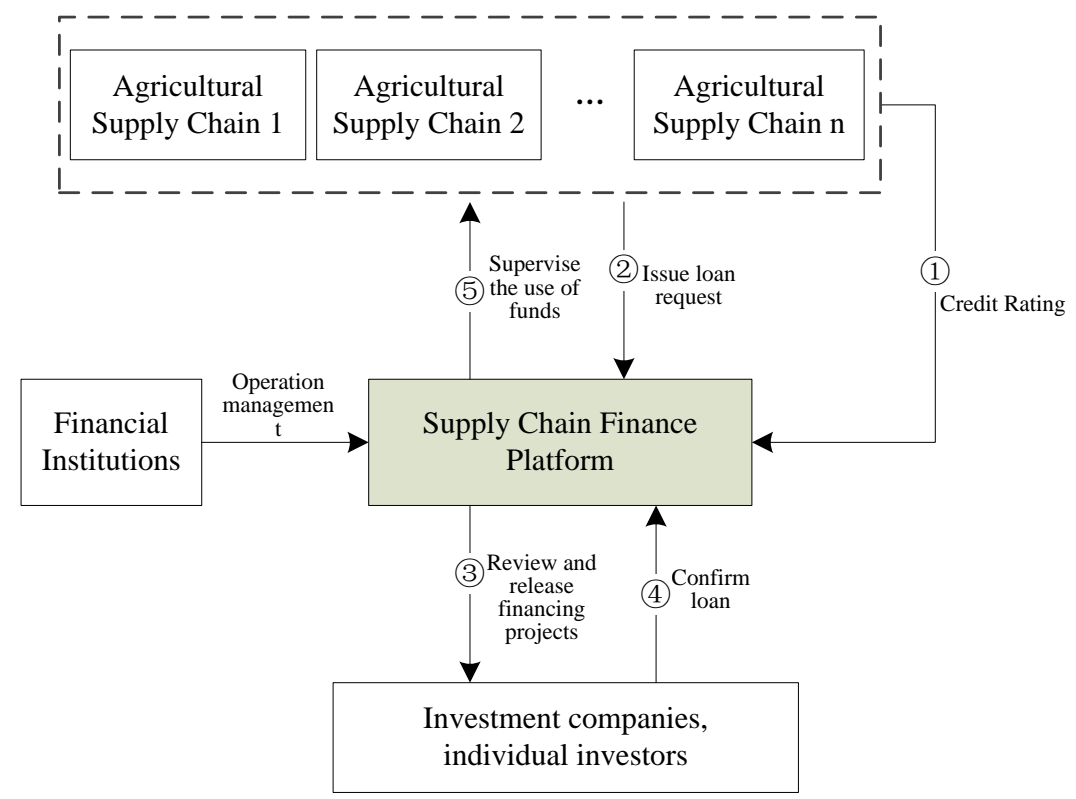

Figure 2 New model of agricultural supply chain finance

\subsection{Operation process of financial model of agricultural product supply chain}

First step, the core company collects information on SMEs in the supply chain, and ranks each company according to the risk rating standards of financial institutions, providing investors with a reference. Second step, fund demand companies release loan requests on the platform. Third step, financial institutions review enterprise qualifications and publish financing projects. Fourth step, investors check credit ratings and confirm loans when they feel reasonable, and deposit funds into supply chain financial platforms. Fifth step, core companies supervise the use of funds, uploads electronic bills, transaction information, receivable bills and other information to the supply chain financial platform, with the help of blockchain technology; investors and financial institutions supervise the use of funds through the supply chain financial platform.

In this way, the financing channels of SMEs have become flexible, and the financing costs are low; financial institutions supervise the repayment of small and medium-sized enterprises on schedule, and collect corresponding commissions; core enterprises have obtained the ability to coordinate and manage the overall supply chain due to the credit rating of small and medium enterprises; idle capital owners and investment companies can know the operation of small and medium-sized enterprises, at the same time, get the corresponding income.

\section{CONCLUSION}

The supply chain financial platform provides a large amount of valuable data for enterprises and individuals to solve the problem of information asymmetry and trust crisis in the supply chain financial operation process.

This supply chain financing model can integrate a large amount of social idle funds, provide loans to SMEs, and solve the problem of financing difficulties for SMEs.

This model internalizes financial institutions into subsidiaries of the enterprise group where the core enterprises in the supply chain are located, thereby reducing information costs, further promoting cooperation between upstream and downstream enterprises in the supply chain, and enhancing the competitiveness of the entire supply chain.

\section{REFERENCES}

[1]. Zhang, R., Shi, H.H. (2019) Agricultural Supply Chain Finance and Innovation of Rural Household 
Financing Mode in China. Journal of Social Science of Harbin Normal University, 51:66-69

[2]. Gu, J., Cheng, X., Deng, X., (2017) Research on Financial Model Innovation of SME Supply Chain. Soft Science, 206:83-86

[3]. Ye, H.L. (2019) Analysis on the Development Path of Agricultural Supply Chain Financial Innovation from the Perspective of Rural Financial Restraint. Journal of Qingdao Agricultural University (Social Science Edition), 23-28 